

Website:

www.jponline.org

DOI:

10.4103/JLP.JLP_60_17
Departments of Hematology and Blood Bank, ${ }^{1}$ Oncology and 2Liaquat National Medical College, Karachi, Pakistan

Address for correspondence: Dr. Sadia Sultan, Department of Hematology and Blood Bank, Liaquat National Hospital and Medical College, Karachi, Pakistan. E-mail: sadiasultan96@ yahoo.com

Submission: 04-04-2017 Accepted: 30-06-2017

\title{
Institutional-based tumor registry of hematopoietic malignancies: A 4 years' preliminary report from Karachi
}

\author{
Sadia Sultan, Syed Mohammed Irfan, Navaira Ali ${ }^{1}$, Neesha Nawaz ${ }^{2}$
}

\begin{abstract}
:
BACKGROUND: Pakistan has a population of over 198 million making it the world's sixth populous country. However, operational population-based cancer registries in Pakistan are lacking. Limited data are available based on institutional or Karachi Cancer Registry from Karachi; however, no exclusive registry for hematological malignancies is established till date. Hence, we decided to conduct a database analysis to determine the frequencies of various hematological cancers in our tertiary care center in Karachi.
\end{abstract}

PATIENTS AND METHODS: Retrospective assessment of 366 patients presented to Hematology Department, Liaquat National Hospital and Medical College from May 2012 to May 2016 with confirmed diagnosis of hematological cancers was performed. Data were retrieved from hospital-based tumor registry. All pro forma was filled by qualified medical research officer, which included demographic data as age, gender, history, disease type, and its stage at presentation.

RESULTS: Male gender was predominant and accounted for $69.9 \%(n=256)$ and female accounted for $30.0 \%(n=110)$ of the total cases with the male-to-female ratio of $\sim 2: 1$. The mean ages of female and male patients were $42.9 \pm 20.7$ and $49.7 \pm 18.1$ years with the median age of 45 and 51.5 years, respectively. In males, the three most frequent malignancies were chronic myeloid leukemia (CML) (16\%), acute lymphoblastic leukemia (ALL), and acute myeloid leukemia (AML) (12.8\% of each). In females, AML was the most common cancer accounting for $21.8 \%$ followed by CML (18.1\%) and ALL (10\%).

CONCLUSIONS: Our institution-based tumor registry indicates CML and AML were the most common cancers in males and females, respectively, followed by ALL. Chronic lymphoid leukemia, unlike in the West, is seen infrequently in our population. National and provisional hematological tumor registry will be beneficial for future health planning and research.

Key words:

Hematological, Karachi, tumor registry

\section{Introduction}

I prose he annual incidence of cancer is - progressively escalating globally, regardless of socioeconomical status, but the mortalit y rates from malignancies are falling in developed countries. Malignancies inflict a noteworthy financial burden on individuals, families, and as a whole on society ${ }^{[1]}$ It is expected that by 2020 , the cancer incidence will be increase to more than 15 million, with anticipated mortality

This is an open access article distributed under the terms of the Creative Commons Attribution-NonCommercial-ShareAlike 3.0 License, which allows others to remix, tweak, and build upon the work non-commercially, as long as the author is credited and the new creations are licensed under the identical terms.

For reprints contact: reprints@medknow.com up to 12 million. ${ }^{[2]}$ It is projected that the cancer incidence, morbidity, and mortality will be more prevails in the developing world by 2020.[2,3]

The distribution of cancers between the developing and the developed countries had been similar previously. ${ }^{[4]}$ However, there are discernible variances in cancers distribution in different regions of the world. Various plausible factors are contributory including racial, ethnical, socioeconomic, genetically, environmental, and cultural

How to cite this article: Sultan S, Irfan SM, Ali N, Nawaz N. Institutional-based tumor registry of hematopoietic malignancies: A 4 years' preliminary report from Karachi. J Lab Physicians 2018;10:168-72. 
variations. ${ }^{[5]}$ It is mandatory that statistics regarding incidence and frequencies of tumors are available before planning about public health measures. ${ }^{[6,7]}$ As tumor rates of one population cannot be applied to develop a cancer control program for another population.

Unfortunately, population-based concrete hematological cancer statistics has never been available for local population in Pakistan. ${ }^{[8]}$ Epidemiological data from Karachi are scarce despite the fact that the major tertiary care hospitals which are the major referral centers for evaluation and treatment of cancerous patients exist here. In the absence of operational registries, the worth of hospital- or institutional-based registries is eminent for systematic collection of data. ${ }^{[9]}$ The institutional tumor registry of the Liaquat National Hospital and Medical College was established in May 2012.

Here, we report a 4 years' institutional-based hematological tumor registry data from a tertiary care hospital in Karachi. As the patients from all over the Karachi belonging to diverse racial groups were come to our centrally located tertiary center, thus our study estimates the existing trends of different hematological cancers in the city.

\section{Patients and Methods}

LNH is ISO 9001:2008 certified with, especially, emphasizes on maintaining all cancer patients records for data entry and analysis. From May 2012 to May 2016, a total of 366 patients with confirmed diagnosis of hematological cancers visited Hematology Department, LNH.

Variables recorded by residents doctors on predesigned questionnaire were the patients MR number, name, age, sex, address, contact numbers, ethnicity, family history for hematological malignancies, and tumor name and stage. All diseases were diagnosed and confirmed based on international standards and using the classification system introduced by the World Health Organization. ${ }^{[10]}$

Patients with another associated malignancy or having relapsed/refractory diseases were excluded from the analysis. All postchemotherapy and radiotherapy cases were not included in the study.

Based on this, a total of 366 subjects with newly diagnosed hematological cancers were included in this analysis. An ethical approval to conduct this analysis was granted by the Institutional Ethical and Review Committee.

\section{Statistics analysis}

Data were assembled and analyzed using the Statistical Package for the Social Sciences version 22.0 (SPSS Inc, Chicago, IL, USA). The results were expressed as mean (standard deviation) for quantitative variables and are presented as frequency and percentages for qualitative variables.

\section{Results}

Over 4 years, 366 patients with hematopoietic malignancies were enrolled in the analysis. Male was predominant and accounted for $69.9 \%(n=256)$ and female accounts for $30.0 \%(n=110)$ of the total 366 cases with the male-to-female ratio of $\sim 2: 1$.

The mean ages of overall patients were $48.60 \pm 18.2$ (range 3-89 years) while median age was 51.0 years. Mean ages of female and male patients were $42.9 \pm 20.7$ and $49.7 \pm 18.1$ years with the median age of 45 and 51.5 years respectively. The age peak at the fifth decade and subsequent at the sixth decade are seen as illustrated in Figure 1.

Chronic myeloid leukemia (CML) constituted major subtype in $61(16.6 \%)$ patients, followed by acute myeloid leukemia (AML) in $57(15.5 \%)$ patients. Acute lymphoblastic leukemia (ALL) and chronic lymphoid leukemia (CLL) were accounted in $44(12.0 \%)$ and $33(9.0 \%)$ patients, respectively. Multiple myeloma was seen in $33(9.0 \%)$ followed by diffuse large B-cell lymphoma (DLBCL) and Hodgkin's lymphoma (HL) in $28(7.6 \%)$ and $21(5.7 \%)$ patients, respectively. Myelodysplastic syndrome was noted in 20 (5.4\%) patients. Myeloproliferative neoplasm including polycythemia vera, essential thrombocythemia, and primary myelofibrosis were seen in 17 (4.6\%), 16 (4.3\%), and $10(2.7 \%)$, respectively. Table 1 depicted the utter spectrum of the encountered hematological malignancies.

In males, the three most frequent malignancies were CML (16\%), ALL, and AML (12.8\% of each). In females, AML was the most common cancer accounting for $21.8 \%$ followed by CML (18.1\%) and ALL (10\%). Figures 2 and 3 have shown the entire distribution of frequent and lesser occurring blood tumors, respectively, according to gender distribution.

\section{Discussion}

Karachi is the largest city of Pakistan, broadly divided into five districts includes the South, Central, West, East, and Malir. ${ }^{[1]}$ Karachi is the most populous city in Pakistan and has the merit of being the district in the country with a fair representation of all racial and ethnic groups. ${ }^{[12]}$ Thus, it can be taken in an account as a sample population of the whole country.

Epidemiological statistics on the incidence of cancer, information of causative factors, and importantly the 
avoidance of these factors provide a basis for cancer control prevention programs. An etiological factor

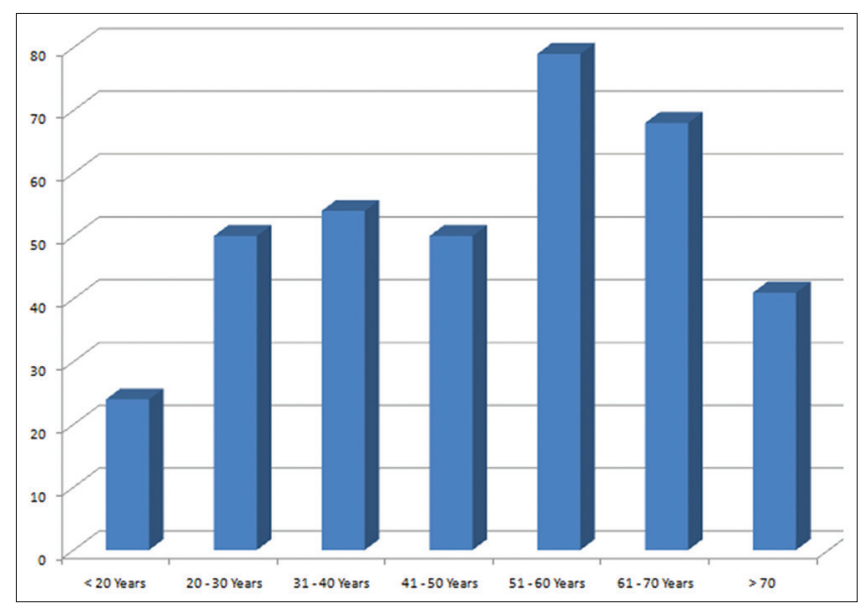

Figure 1: Overall age distribution of hematological cancers

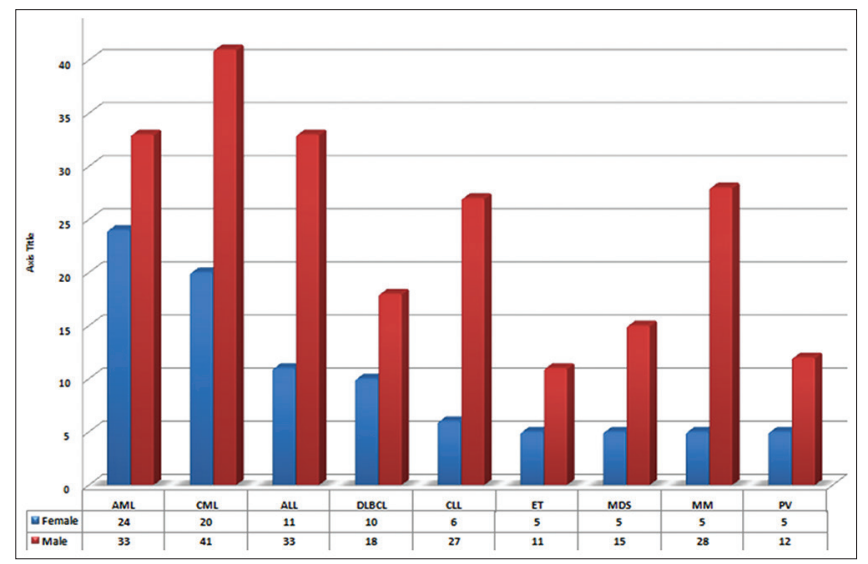

Figure 2: Frequent hematological cancers in Karachi markedly varies in the different countries. The prime objective of "population-based tumor registries" is to provide epidemiological data and identify these risk factors, which is crucial for the assessment of the cancer magnitude.

Table 1: Distribution of all hematological tumors

\begin{tabular}{|c|c|c|c|c|}
\hline Diagnosis & Female & Male & Total (\%) & Mean age \\
\hline $\mathrm{CML}$ & 20 & 41 & $61(16.6)$ & 44.1 \\
\hline AML & 24 & 33 & $57(15.5)$ & 42.0 \\
\hline ALL & 11 & 33 & $44(12.0)$ & 34.3 \\
\hline CLL & 6 & 27 & $33(9.0)$ & 64.2 \\
\hline MM & 5 & 28 & $33(9.0)$ & 58.1 \\
\hline DLBCL & 10 & 18 & $28(7.6)$ & 52.6 \\
\hline Hodgkin's & 4 & 17 & $21(5.7)$ & 39.7 \\
\hline MDS & 5 & 15 & $20(5.4)$ & 55.4 \\
\hline PV & 5 & 12 & $17(4.6)$ & 56.2 \\
\hline ET & 5 & 11 & $16(4.3)$ & 56.5 \\
\hline Myelofibrosis & 2 & 8 & $10(2.7)$ & 58.2 \\
\hline APL & 4 & 2 & $6(1.6)$ & 20.5 \\
\hline FL & 2 & 2 & $4(1.0)$ & 48.0 \\
\hline WM & 2 & 1 & $3(0.8)$ & 60.0 \\
\hline SLL & 1 & 2 & $3(0.8)$ & 51.0 \\
\hline Mantle lymphoma & 1 & 2 & $3(0.8)$ & 69.3 \\
\hline Lambda disease & 1 & 1 & $2(0.5)$ & 65.4 \\
\hline T-cell lymphoma & 1 & 1 & $2(0.5)$ & 49.0 \\
\hline NHL splenic & 1 & 0 & $1(0.2)$ & 68.9 \\
\hline HLH & 0 & 1 & $1(0.2)$ & 54.0 \\
\hline Marginal lymphoma & 0 & 1 & $1(0.2)$ & 71.0 \\
\hline Total & 110 & 256 & $366(100)$ & 48.6 \\
\hline
\end{tabular}

$\mathrm{CML}=$ Chronic myeloid leukemia, $\mathrm{AML}=$ Acute myeloid leukemia, $\mathrm{ALL}=$ Acute lymphoblastic leukemia, CLL=Chronic lymphoid leukemia, MM=Multiple myeloma, DLBCL=Diffuse large B-cell lymphoma, MDS=Myelodysplastic syndrome, $\mathrm{PV}=$ Polycythemia vera, $\mathrm{ET}=$ Essential thrombocythemia, $\mathrm{APL}=$ Acute promyelocytic leukemia, FL=Follicular lymphoma, SLL=Small lymphocytic lymphoma, NHL=Non-Hodgkin's Iymphoma, HLH=Hemophagocytic lymphohistiocytosis, WM=Waldenstrom macroglobulimemia

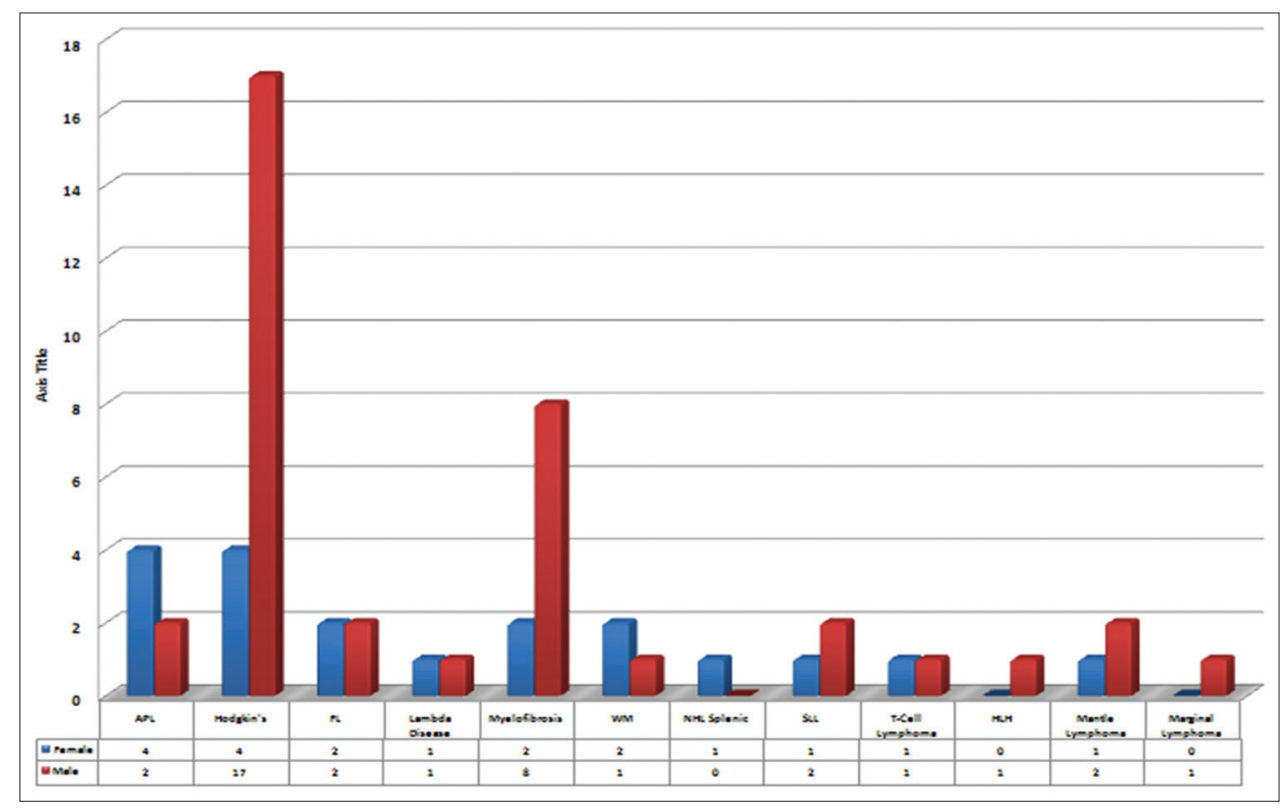

Figure 3: Less frequent hematological cancers in Karachi 
Malignancy is the primary cause of mortality in the developed countries and the second principal cause of decease in developing countries. ${ }^{[13]}$ The burden of cancer is gradually rising in the underdeveloped countries. To the date, there have been a few studies in the regional literature on hematological tumor spectrum. To the best of our knowledge, this is the first report from our part of the world. Previously published studies from Pakistan mainly addressed individual cancers but did not look into insight of entire spectrum.

Hematological malignancies, in particular leukemias, and non-HL (NHL) are more common in the Southeast Asia vicinity compared with USA and European localities. ${ }^{[14]}$ In a prior study conducted in Northern Pakistan at Armed Forces Institute of Pathology, leukemias were the second most common malignancy seen in the adult male patient population and the $4^{\text {th }}$ most common malignancy in the adult female patients. ${ }^{[14]}$

Data from Abbottabad reported leukemia to be the first most common malignancy in adult patients of both gender. ${ }^{[15]}$ This is in disparity to the data based on National Cancer Institute-SEER stats (2009-2013) which reported leukemia to be an uncommon form of malignancy affecting 13.5/100,000 in the United States yearly. ${ }^{[16]} \mathrm{CML}(16.6 \%)$ in our experience was twice more common as CLL $(9.0 \%)$. The disease also affected a much younger age group with the mean age of 44 years. This is in distinction to the Western reports where CLL is seen more frequently than CML rather we determined CLL as a least common of all leukemias. ${ }^{[17]}$ This difference may be due to some underlying genetic predisposition or environmental factor responsible for a particular subtype of leukemia in our population.

AML was the second frequent malignancy being more common than ALL in our study. In China, AML is three times more common than ALL. ${ }^{[18,19]}$ AML and ALL had a male preponderance similar to that reported in literature ${ }^{[14]}$ In our patients, peak incidence of AML is seen in the fourth decade of life with no progressive increase in incidence with advancing age. Similar observations have been reported by previously published studies, from Pakistan also revealed comparable age at presentation; 38 and 39 years, respectively. ${ }^{[20,21]}$

The incidence of lymphoma increasing world widely largely due to increasing prevalence of NHL. HL accounts for about $10 \%$ of all lymphomas and the remaining $90 \%$ are constituted by NHL. ${ }^{[22]}$ We also determined NHL as a frequent type of lymphoma with DLBCL predominance as reported previously.

Our study had certain limitations; relatively small sample size, lack of data to ascertain the etiological factors, and also lacking of follow-up data. Despite the limitations, this is the first preliminary report stating hematological cancer spectrum in the Pakistani patients. Hematological cancer trends in Karachi show preponderance of CML and AML affecting much younger age group. Study can act as a baseline for designing future prospective studies in the country. It is a dire need for a population-based hematology tumor registry for the planning, establishment and monitoring of the cancer control programs.

\section{Acknowledgment}

The authors express their gratitude and appreciation to the individuals and their families who contributed in this project. We would like to express our special thanks of Mr. Asif Hameed for statistical analysis for this study.

\section{Financial support and sponsorship \\ Nil.}

\section{Conflicts of interest}

There are no conflicts of interest.

\section{References}

1. Kim SY, Park JH, Kang KH, Hwang I, Yang HK, Won YJ, et al. The economic burden of cancer in Korea in 2009. Asian Pac J Cancer Prev 2015;16:1295-301.

2. Kanavos P. The rising burden of cancer in the developing world. Ann Oncol 2006;17 Suppl 8:viii15-viii23.

3. Talaiezadeh A, Tabesh H, Sattari A, Ebrahimi S. Cancer incidence in southwest of Iran: First report from Khuzestan population-based cancer registry, 2002-2009. Asian Pac J Cancer Prev 2013;14:7517-22.

4. Aziz Z, Sana S, Saeed S, Akram M. Institution based tumor registry from Punjab: Five year data based analysis. J Pak Med Assoc 2003;53:350-3.

5. Satariano WA, Swanson GM. Racial differences in cancer incidence: The significance of age-specific patterns. Cancer 1988;62:2640-53.

6. Masood K, Masood A, Zafar J, Shahid A, Kamran M, Murad S, et al. Trends and analysis of cancer incidence for common male and female cancers in the population of Punjab province of Pakistan during 1984 to 2014. Asian Pac J Cancer Prev 2015;16:5297-304.

7. Bal MS, Bodal VK, Kaur J, Kaur M, Sharma S. Patterns of cancer: A study of 500 Punjabi patients. Asian Pac J Cancer Prev 2015;16:5107-10.

8. Hanif M, Zaidi P, Kamal S, Hameed A. Institution-based cancer incidence in a local population in Pakistan: Nine year data analysis. Asian Pac J Cancer Prev 2009;10:227-30.

9. JamalS, Atique M, Khadim MT. Changing pattern of malignancies: Analysis of histopathology based tumour registry data and comparison of three decades at Armed Forces Institute of Pathology, Rawalpindi, Pakistan. J Pak Med Assoc 2014;64:24-7.

10. Swerdlow SH, Campo E, Harris NL, Jaffe ES, Pileri SA, Stein H, et al. WHO Classification of Tumors: Pathology and Genetics of Tumors of Haematopoietic and Lymphoid Tissues. Lyon: IARC Press; 2008.

11. Bhurgri Y. Karachi Cancer Registry Data - Implications for the National Cancer Control Program of Pakistan. Asian Pac J Cancer Prev 2004;5:77-82.

12. Karachi City-Wikipedia, The Free Encyclopedia. Available form: 
http:/ / www.karachiwikepedia.com. [Last accessed on 2016 Dec 30].

13. Jemal A, Bray F, Center MM, Ferlay J, Ward E, Forman D. Global cancer statistics. CA Cancer J Clin 2011;61:69-90.

14. Khalid A, Zahid M, Rehman A, Ahmad ZU, Qazi S, Aziz Z. Clinicoepidemiological features of adult leukemias in Pakistan. J Pak Med Assoc 1997;47:119-22.

15. Ahmad S, Qureshi AN, Kazmi A, Rasool A, Gul M, Ashfaq M, et al. First cancer statistics report from Hazara division. J Ayub Med Coll Abbottabad 2013;25:71-3.

16. National Cancer Institute (NCI), Surveillance, Epidemiology and end Results Program, SEER Stat Facts Sheets, Leukemia. U.S Department of Health and Human Services; 2013.

17. Le Guyader-Peyrou S, Belot A, Maynadié M, Binder-Foucard F, Remontet L, Troussard X, et al. Cancer incidence in France over the 1980-2012 period: Hematological malignancies. Rev Epidemiol Sante Publique 2016;64:103-12.
18. Clinical Collaborative Group, Hematological Branch of Fujian Medical Association. An epidemiological investigation of adult acute leukemia in Fujian Province in 2010. Zhonghua Xue Ye Xue Za Zhi 2012;33:902-5.

19. Clinical Collaborative Group of Fujian Medical Association Hematological Branch. Incidence of newly diagnosed adult acute leukemia in Fujian province from 2011 to 2012. Zhonghua Xue Ye Xue Za Zhi 2015;36:733-8.

20. Harani MS, Adil SN, Shaikh MU, Kakepoto GN, Khurshid M. Frequency of fab subtypes in acute myeloid leukemia patients at Aga Khan University Hospital Karachi. J Ayub Med Coll Abbottabad 2005;17:26-9.

21. Sultan S, Zaheer HA, Irfan SM, Ashar S. Demographic and clinical characteristics of adult acute myeloid leukemia - Tertiary care experience. Asian Pac J Cancer Prev 2016;17:357-60.

22. Shankland KR, Armitage JO, Hancock BW. Non-Hodgkin lymphoma. Lancet 2012;380:848-57. 